\title{
Stabilisation of river dykes with drainage elements
}

\author{
T. Riegger ${ }^{1}$, A. Bieberstein ${ }^{1}$, F. Hörtkorn ${ }^{2}$, and H.-G. Kempfert ${ }^{2}$ \\ ${ }^{1}$ Institute for Soil Mechanics and Rock Mechanics, Karlsruhe Institute of Technology (KIT), Karlsruhe, Germany \\ ${ }^{2}$ Institute of Geotechnics and Geohydraulics, University of Kassel, Kassel, Germany
}

Received: 16 March 2009 - Revised: 2 October 2009 - Accepted: 17 October 2009 - Published: 7 December 2009

\begin{abstract}
In recent times, enormous damage has been caused by dyke failures during and after river flood disasters throughout the world. Besides extreme meteorological conditions the reasons for these failures are inadequate design and the actual condition of affected dyke structures.

To minimize the occurrence of dyke failures in future, in a national BMBF research project (BMBF: German Federal Ministry of Education and Research) an alternative stabilisation technique has been investigated as an instrument for short term refurbishment and as an improvement to existing and endangered dyke structures.

It is intended to improve the stability of dyke structures by the mechanical installation of drainage devices, thus preventing dyke failure by controlling the seepage in the structure.

Within the scope of this paper selected results concerning stabilizing capability and feasibility of the stabilisation technique are presented in detail. Concerning feasibility the focus is placed on natural scale model tests to verify numerical calculations and to investigate the suitability of the adapted installation methods in situ.
\end{abstract}

\section{Introduction}

During floods, dyke failures resulting in considerable damage have been a common occurrence in recent years (cf. Münchner Rück, 2008). Besides extreme meteorological conditions, ageing and the bad design of dyke structures must be considered as the main reasons for failures (cf. TUD, 2005). In order to minimize at least the monetary damage caused by future floods, a rehabilitation of dyke structures is therefore necessary. However, an overall rehabilitation of dyke systems, with several thousand kilometres of dyke structures in Germany alone, can only be realized on a longterm basis due to the considerable costs. Therefore short term

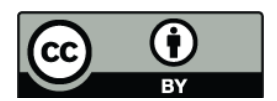

Correspondence to: T. Riegger

(tobias.riegger@kit.edu) stabilisation techniques are required to improve the stability in critical dyke sections as an intermediate rehabilitation measure. At best short term stabilisation techniques enable the local authorities to stabilize critical dyke sections days in advance or even during flood events.

In a national BMBF joint research project (BMBF: German Federal Ministry of Education and Research), stabilisation techniques are being developed to improve the stability of dykes by the subsequent mechanical installation of drainage elements, thus preventing dyke failure by controlling the seepage in the structure. An additional target was to develop innovative geosynthetic structures to be used as drainage elements.

Besides the verification of the feasibility, design charts have to be provided to ensure later industrial implementation. Therefore the necessary data basis is being created by means of numerical parameter studies. The results of the calculations are verified by model tests in the laboratory and by means of dyke models on a technical scale. Furthermore, the possible additional stabilizing impacts as reinforcement effects due to the drainage element itself and suction effects caused by the drainage are being investigated and quantified in model tests.

In order to achieve the defined targets, the joint project was divided into three main sections - a) Hydraulics, b) Stability, c) Drainage Elements - each under the responsibility of one partner. The University of Karlsruhe has investigated the hydraulic impact of drainage elements on the seepage regime in the dyke structure. The University of Kassel has quantified the effects of the drainage elements on the stability of the landside slope, particularly by lowering the seepage surface in the structure, by reinforcement and suction. The task of the Saxon Textile Research Institute (STFI), located in Chemnitz, has been to create drainage elements based on geosynthetic structures which are cost effective and simple to install.

Within the scope of this paper selected results concerning the stabilizing capability and feasibility of the stabilisation technique are presented in detail. 


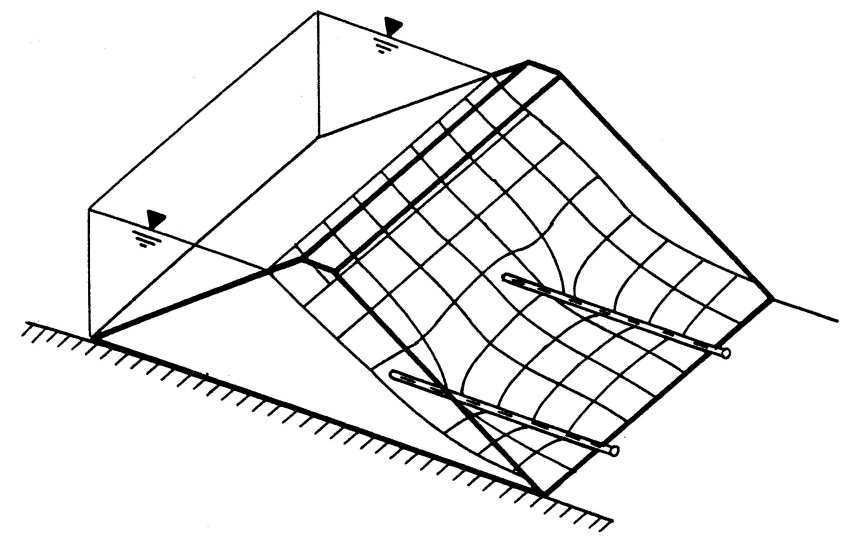

Fig. 1. Illustration of the phreatic surface in a dam with drainage elements (from Brauns and Gottheil, 1989).

\section{General principle (of the stabilization technique)}

It is a generally known method to stabilize slopes under hydraulic impact by intercepting the seepage water with horizontal drains (Cedergren, 1988). According to Smith (1957) horizontal drainage elements have been used successfully for slope stabilization in California since 1939. Design charts have been developed by several authors as a design aid to determine an adequate distance and length of the drainage elements. Experimental verification has been mostly achieved by small scale model tests (Kenney et al., 1977; Resnik and Znidarcic, 1990). Concerning the drainage materials, primarily papers with an agricultural background can be found. Dierickx (1993) provides an overview of the recent research and development on drainage and envelope materials.

Brauns and Gottheil (1989) have presented quantitative results concerning the hydraulic effects of drain pipes in homogeneous embankment dams. The installation of drainage elements (pipes) in dam or dyke structures induces a three dimensional phreatic surface as shown in Fig. 1. Besides the desired (spatially variable) drawdown of the phreatic surface, the installation of drainage elements leads to an increase in the system permeability and consequently to an increase in the seepage quantity - concerning dykes this effect is negligible in most cases. The drawdown of the phreatic surface as well as an increase in the seepage quantity depends on the distance between the drainage elements and their length.

By adapting this principal method, the subsequent installation of drainage elements in dyke structures can be a cost and time effective method for the short term stabilization of critical dyke sections. In Fig. 2 a possible practical implementation of the above mentioned general stabilisation technique for the sectional rehabilitation of river dykes is shown in a sketch. To achieve an efficient installation performance - which means up to $500 \mathrm{~m}$ of rehabilitated dyke section per day - the installation of the drainage elements is executed by a drilling crawler.



Fig. 2. Stabilization of river dykes by means of subsequently installed drainage elements (sketch).

\section{Quantification of stabilizing effects (stabilizing capability)}

One main target of the research project was to quantify the achievable stabilizing effects of this stabilization method by means of a numerical parameter study. In a second step the results of the parameter study could be used for the development of an engineering method (design charts) in order to enable the applicant to design the rehabilitation of a river dyke section by means of drainage elements (cf. Fig. 2).

Taking the hydraulic impact into consideration, different working stages had to be carried out in order to achieve this aim. Basic numerical calculations (2-D- and 3-Dcalculations) confirmed the essential lowering capacity of drainage elements with a defined length and diameter to be arranged at regular intervals near the foundation of a river dyke. After verifying the numerical calculations - in particular the modelling of the drainage elements - by means of small scale hydraulic model tests, a numerical parameter analysis was carried out. The effects of various lengths $(2.25 \mathrm{~m}, 4.5 \mathrm{~m}, 6.75 \mathrm{~m}, 9 \mathrm{~m})$ and distances between drainage elements ( $1 \mathrm{~m}$ up to $10 \mathrm{~m}$ ) on the phreatic surface of the seepage and on the draining capacity were examined. Hydraulic calculations were carried out by using the commercially available finite-element-based Software SPRING (delta-h). The calculation of the flow in the unsaturated zones is done with the Richards equation by using the van GenuchtenMualem-parameterization of the soil water retention curve.

The geometry of the dyke structure was defined according to the conditions of aged dyke structures in Germany. It was assumed that the dyke structures were homogeneous and isotropic and that they were standing on an impervious foundation. The resulting geometry of the dyke structure and the applied predefined soil parameters are shown in Fig. 3. The hydraulic load on the upstream slope corresponds to a water table at crest level. Parameter analyses were carried out for both, sandy and loamy dyke structures. 


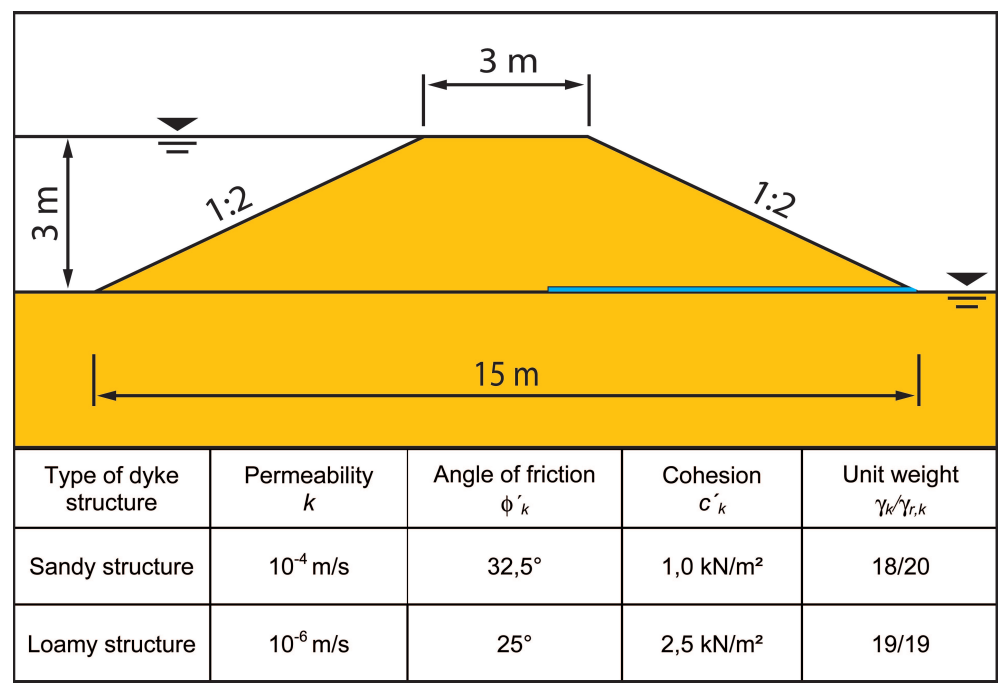

Fig. 3. Geometry of dyke structure and material parameters in parameter study.

The results of the hydraulic parameter analyses were transferred to the partner project at the University of Kassel to analyze the effects on stability in a second stage of the parameter analysis. 3-D-data of pore water pressure distributions and locations of the phreatic surface dependent on the respective length and distance combination were provided for stability calculations.

The resulting slope stabilities were determined by analytical stability analysis in 2-D and 3-D using the commercially available software CLARA-W.

CLARA-W is based on the extension of standard Limit Equilibrium methods to three dimensions (Hungr, 1987). In the stability analysis 3-D-pore water pressures in the form of 3-D-phreatic surfaces and spatial limited (regional or 3-D) failure mechanisms were taken into account.

In Table 1 the results of 2-D- and 3-D-stability analysis in terms of global safety factors are given for a sandy dyke structure, where the drainage elements are $6.75 \mathrm{~m}$ long and where there are varying distances between the drainage elements ranging from $1 \mathrm{~m}$ up to $10 \mathrm{~m}$.

Describing the calculated slope stability the global safety factor (against failure) is defined as the ratio of the sum of resisting forces or moments to the sum of activating forces or moments (Cedergren, 1988).

2-D-stability analyses were made for a cross section located at the axis of the drainage element (favourable cross section) and a cross section in the centre between the drainage elements (unfavourable cross section). These results represent the drawdown effect of seepage on stability. Additional stabilizing effects caused by reinforcement and suction were overlooked in the stability analysis.
Table 1. Resulting global safety factors (length of drainage element $6.75 \mathrm{~m})$.

\begin{tabular}{lccc}
\hline $\begin{array}{c}\text { Distance between } \\
\text { drainage elements }\end{array}$ & $\begin{array}{c}\text { 2-D-Analysis } \\
\text { Cross section } \\
\text { in axis of } \\
\text { drainage } \\
\text { element }\end{array}$ & $\begin{array}{c}\text { 2-D-Analysis } \\
\text { Cross section } \\
\text { in the center } \\
\text { between two } \\
\text { drainage } \\
\text { elements }\end{array}$ & \\
\hline Distance $a=1 \mathrm{~m}$ & 1.66 & 1.66 & 1.66 \\
Distance $a=2 \mathrm{~m}$ & 1.66 & 1.66 & 1.66 \\
Distance $a=3 \mathrm{~m}$ & 1.66 & 1.66 & 1.66 \\
Distance $a=4 \mathrm{~m}$ & 1.66 & 1.60 & 1.66 \\
Distance $a=5 \mathrm{~m}$ & 1.66 & 1.51 & 1.60 \\
Distance $a=7 \mathrm{~m}$ & 1.66 & 1.34 & 1.45 \\
Distance $a=10 \mathrm{~m}$ & 1.66 & 1.17 & 1.32 \\
\hline
\end{tabular}

Compared to an identical dyke structure without drainage elements, significant stabilizing effects can be observed in a rehabilitated dyke depending on the length/distance combinations of the drainage elements. The global safety factor increases from 1.0 (homogeneous dyke structure) up to 1.66 - depending on the distance between the drainage elements (cf. Table 1). Corresponding steady state seepage lines for the center cross section are shown in Fig. 4. The length of the drainage elements is $6.75 \mathrm{~m}$ and the distance between the drainage elements ranges from $1 \mathrm{~m}$ to $10 \mathrm{~m}$.

Based on the numerical results it can be concluded, that even for extreme steady state seepage conditions - according to up-to-date technical standards (in Germany) - the rehabilitation of critical homogeneous dyke sections can be achieved by the subsequent installation of drainage elements. 


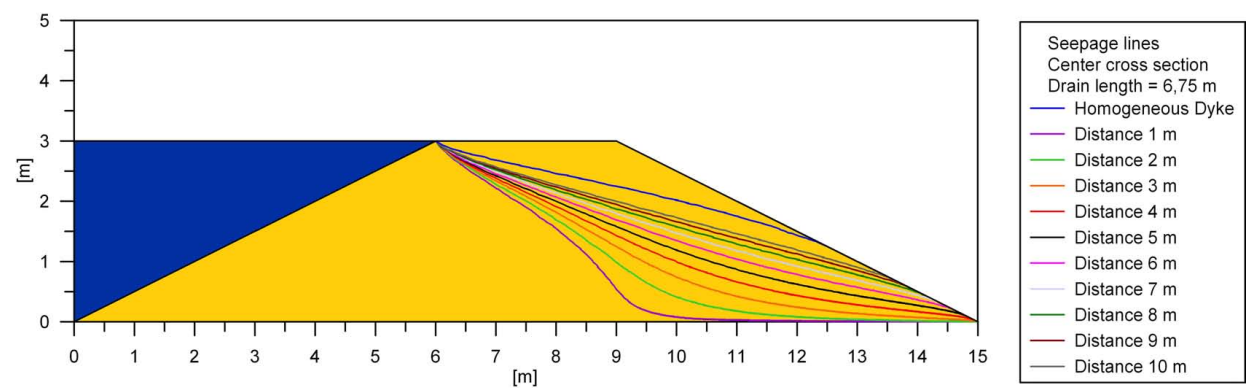

Fig. 4. Calculated steady state seepage lines for dyke structures with drainage elements at varying distances (centre cross section between adjacent drainage elements; length of drainage element: $6.75 \mathrm{~m}$ ) and for a corresponding homogeneous dyke structure (no drainage element).

\section{Installation technique (technical feasibility)}

\subsection{General aspects and requirements}

In addition to the confirmation of sufficient stabilizing capabilities, i.e. sufficient drawdown of the phreatic surface, a suitable installation technique adapted to the chosen drainage elements is an important aspect for ensuring the feasibility of stabilizing quasi-homogeneous dyke structures with drainage elements.

Slotted PVC-drainage-pipes - 2 inches in diameter - are considered as standard drainage elements. Besides their cost effectiveness, PVC-drainage-pipes can be implemented for a wide spectrum of soil materials. According to empiric filter criteria (Cedergren, 1988) the slot width has to be adapted to the soil material in order to prevent negative erosion effects.

In addition to the drainage-pipes discussed in this paper other types of drainage elements can be used for this stabilisation technique. For example wick-drains made of geosynthectic textiles could be a possible alternative - especially when used in fine soils. Disadvantages of that type of drainage element are a - compared to drainage-pipes - low discharge capacity and no possibility of inspection and maintenance after installation.

The basic requirements of a suitable installation technique are cost effectiveness, the possibility of horizontal installation at a minimum height above the dyke foundation and a minimum influence on the drainage capacity of the drainage element combined with sufficient accuracy.

To verify both, the feasibility of the installation technique and the hydraulic performance of subsequently installed drainage elements, tests were carried out by means of dyke models on a natural scale. The geometry of the dyke models was identical to the boundary conditions of the numerical parameter study (cf. Fig. 3). The soil material of the model dyke structures was a silty sand with about $10 \%$ fines.

\subsection{Installation tests (dry conditions)}

In the first step, installation tests were carried out on a dyke model in "dry condition", which means the soil material had a natural water content. The installation of the drainage ele- ments was executed by means of a standard drilling crawler (cf. Fig. 5a). Considering the above mentioned basic requirements and the positive results of preliminary tests, the drainage elements were installed by using a lost drill bit. The basic principle of the applied installation method is shown in Fig. 6. Using a driving rod the drainage element firmly connected to the lost drill bit is driven into the dyke structure. Soil material is not extracted. The drainage element is installed by means of soil displacement. Already during the installation process the drainage element comes into direct contact with the surrounding soil material. Thus voids along the drainage elements caused by the installation process as possible seepage channels and trigger of piping are prevented. The disadvantages of this installation method, like the compaction of surrounding soil material and the resulting changes in permeability, were not considered as being critical. A later excavation of the installed drainage elements showed that the installation method was well accurate. Significant changes in density in the surrounding area of the drainage element could not be detected. Density tests were carried out with samples (diameter: $30 \mathrm{~mm}$ ) taken at different distances to the axis of the drainage elements. Due to the rather coarse resolution of this method, significant density changes in the ultimate vicinity of the drainage element could not be investigated.

\subsection{Installation tests (steady state seepage conditions)}

After the positive tests concerning the accuracy and effects on density in dry conditions, one drainage element was installed in a flooded dyke model on a natural scale under steady state seepage conditions (cf. Fig. 5b). Multiple measurement devices such as TDR-Sensors (Scheuermann et al., 2001, 2008; Woersching et al., 2006), tensiometers and a hydraulic gauge in the centre of the dyke permitted a spatial investigation of the seepage conditions inside the dyke structure. The positions of the measurement devices as well as installed drainage elements are shown in Fig. 7.

Special emphasis was laid on the investigation of the development of additional pore water pressures resulting from the installation process under steady state seepage conditions (flooded dyke structure), as well as on the hydraulic perfor- 



Fig. 5. Investigations on dyke models on a natural scale: (a) installation of drainage elements in dry conditions, (b) dyke model on a natural scale for tests with hydraulic load (view to downstream slope).

mance of the drainage elements and spatial effects on the phreatic surface. Measurement data was also used for a final verification of the numerical calculations. Tensiometer data could be used directly for the quantification of suction effects.

In order to evaluate the hydraulic performance of the subsequently installed drainage element (cf. Fig. 7; drainage element I), the outer drainage elements (Fig. 7; drainage elements II), which had been previously filled with soil material, were installed during the construction of the dyke structure. Later they were (hydraulically) activated by extracting the soil material, and their hydraulic performance was compared to the subsequently installed drainage element $\mathrm{I}$ in the centre of the dyke.

During the installation process under steady state seepage conditions, an immediate increase in the pore water pressures was observed, but the magnitude of increase - about a max-



Fig. 6. Installation-Test-A - sketch of installation method.

imum of $1 \mathrm{kPa}$, which corresponds to an increase of about $6 \%$ of the pore water pressure, before starting the installation process - was not critical. Immediately after completing the installation of the drainage element, the pore water pressures dropped back to their original level (corresponding to steady state seepage conditions).

The tensiometer measurement results (cf. Fig. 7; centre cross section A-A) for steady state seepage conditions with (one) activated centre drainage element (I) only and homogeneous steady state seepage conditions (no drainage element activated) were almost identical. In Fig. 8 these tensiometer measurement results correspond well to a seepage line calculated for the steady state conditions of a homogeneous dyke structure, i.e. where there is no drainage element in the structure.

After also activating the outer drainage elements (II) (all three drainage elements activated), a significant drawdown of the phreatic surface could be observed. The corresponding tensiometer measurement results (in a steady state) match with the calculated seepage line for steady state conditions where only the two outer drainage elements are activated (cf. B) in Fig. 8.

When comparing the hydraulic performance of the installed drainage element in the centre with the hydraulic performance of the outer drainage elements, a significant difference was observed. Seepage quantities of the centre drainage element amount to only $10 \%$ of the seepage quantities of the outer drainage elements.

In conclusion it can be stated, that the hydraulic impact of the installed drainage element in the centre on the phreatic surface is insignificant. The good match of the hydraulic performance of the outer drainage elements with the numeric hydraulic model is a final verification of the numerical calculations on a natural scale. It is assumed that the inadequate hydraulic performance of the centre drainage element is caused by the installation method applied (cf. Fig. 6). The possible effects on the hydraulic performance of the drainage element related to the installation method can be a compaction of soil in the immediate vicinity of the drainage element (which could not be investigated in previous tests), the clogging of drainage slots by soil particles or the relocation of fines by mechanical excitation during the installation process. 



Fig. 7. Dyke model on a natural scale - arrangement of measuring devices and drainage elements - horizontal section at foundation level.



Fig. 8. Comparison of calculated seepage lines, A) no drain activated and B) outer drains activated, with tensiometer measurement results (cross section A - A at dyke center, cf. Fig. 7).

\subsection{Additional installation tests (steady state seepage conditions)}

Considering the results of the previous installation tests, a more suitable installation method had to be found especially with less impact on the hydraulic performance of the drainage element. Another important conclusion of the previous installation tests was the necessity for hydraulic tests after installation of the drainage elements, since effects caused by the installation method influencing the hydraulic performance of the drainage elements could not be detected under dry conditions.
Due to the limited budget - additional installation tests were not foreseen in the conception phase of the project combined installation and hydraulic tests were run on a natural scale (Installation-Test-B), but the geometry of model dykes had to be modified as illustrated in Fig. 9. For better cost efficiency, the tests were carried out simultaneously in four standard transport containers. The goal of these tests was to find an installation method with a sufficiently low impact on the hydraulic performance of the installed drainage element to achieve the required (calculated) drawdown of the phreatic surface. Four different installation methods were investigated. 

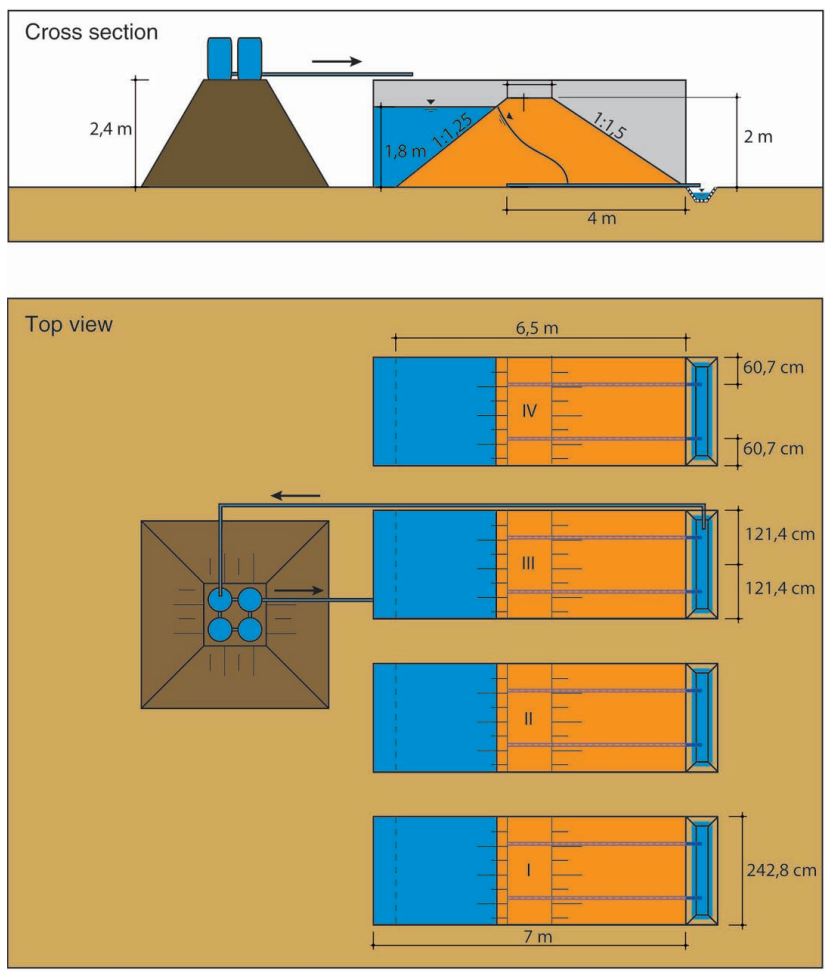

Fig. 9. Additional installation tests (Installation-Test-B).

Basic sketches of the installation methods are shown in Fig. 10. All four installation methods include the excavation of soil to prevent or at least minimize any compaction induced by the installation process. First an unsupported (except for Method 4) borehole is made using a drilling auger. In a second step the drainage element is installed in the unsupported borehole after retracting the drilling auger. In Method 4 the excavation of the soil by the drilling auger and the installation of the drainage element are carried out inside a supporting tube which is withdrawn afterwards. Thus, any contact between the drainage element and the soil during installation is minimized and therefore also any clogging of the drainage slots.

Installation Methods 2 and 4 imply voids along the installed drainage elements due to the larger diameter of the drilling auger and of the supporting tube respectively (cf. Fig. 10). To prevent uncontrolled seepage along the installed drainage element the voids along the drainage element were backfilled on the last meter to the downstream slope.

According to the four different installation methods, four drainage elements were installed in four separate model dykes under dry conditions - each one being placed in a container (cf. Fig. 9). In a second step, hydraulic tests were carried out - the dyke models were flooded. After reaching steady state seepage conditions, the seepage quantities of each installed drainage element (Drainage element B) were compared to the corresponding seepage quantities of a sec-
Installation-Test-B Method 1
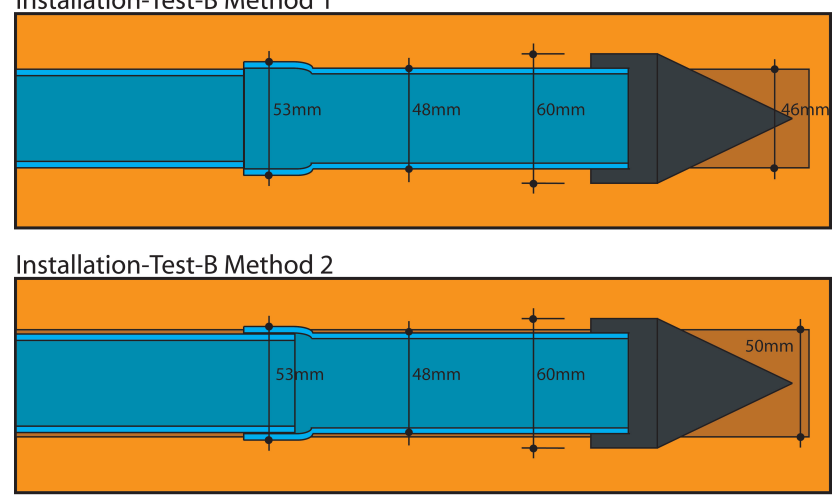

Installation-Test-B Method 3

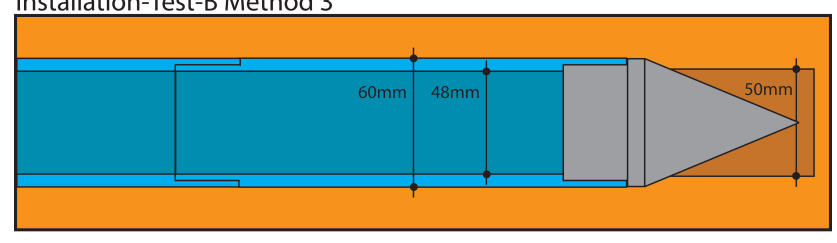

Installation-Test-B Method 4

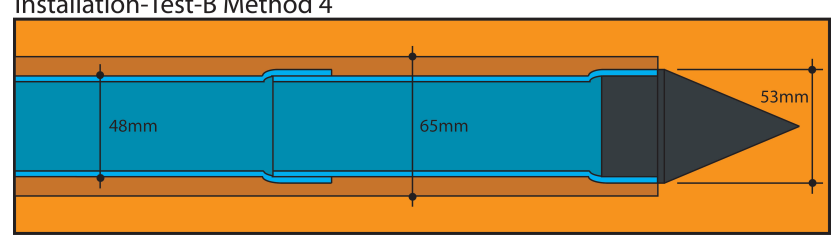

Fig. 10. Installation-Test-B - sketches of installation methods investigated.

ond drainage element (Drainage element A) in each container installed during the construction of each model dyke. All drainage elements had a length of $4.0 \mathrm{~m}$.

The best hydraulic performance was achieved with Method 4 (ratio of seepage quantity: 0.5 - the seepage quantities of the subsequently installed drainage element were $50 \%$ of the seepage quantities of the previously installed drainage element). Method 3 - with possibly the strongest contact between the drainage element and the surrounding soil during installation - yields only a ratio of seepage quantities of 0.1. Furthermore, the ratio of the seepage quantity achieved for Method 1 was 0.3 and for Method 2 it was 0.4 . It can therefore be stated, that the prevention of clogging during the installation process and diminished physical contact between drainage element and surrounding soil has a significant impact on the hydraulic performance of drainage elements.

To estimate the effect of a reduced hydraulic performance of the installed drainage element on the drawdown of the phreatic surface, comparative numerical calculations were made for each installation test. The geometry of the numerical model corresponds to the model tests (Installation-Test-B). 
Container I / Installation-Test-B Method 1

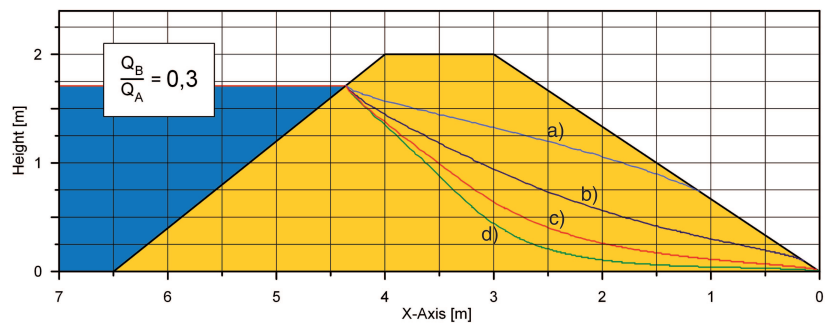

Container II / Installation-Test-B Method 2

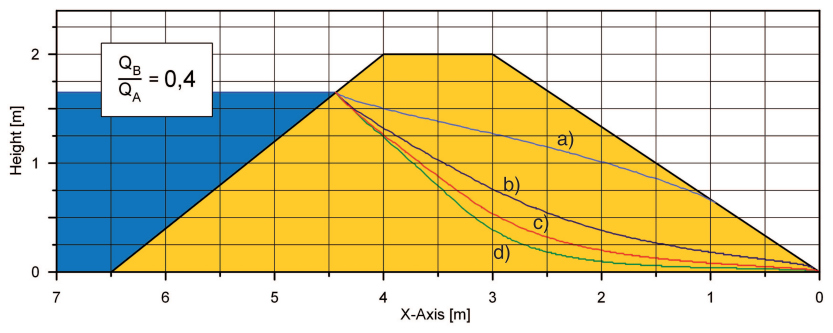

Container III / Installation-Test-B Method 3



Container IV / Installation-Test-B Method 4



Fig. 11. Installation-Test-B - comparison of calculated seepage lines: a) - homogeneous dyke structure, b) - two drainage elements with reduced hydraulic performance as measured, c) - one drainage element with full hydraulic performance one drainage element with reduced hydraulic performance as measured, d) - two drainage elements with full hydraulic performance.

For each installation test the seepage lines calculated in the centre cross section between two adjacent drainage elements (length $4.0 \mathrm{~m}$ ) are shown in Fig. 11 for four cases respectively:

a) Homogeneous dyke structure with no drainage elements. b) Two drainage elements with a reduced hydraulic performance as measured.

c) One drainage element with full hydraulic performance adjacent to one drainage element with a reduced hydraulic performance as measured.

d) Two drainage elements with full hydraulic performance.

The results of the numerical calculations show a distinct connection between hydraulic performance $\left(Q_{B} / Q_{A}\right)$ of the drainage elements and the resulting drawdown of the phreatic surface, respectively.

For Installation-Test-B Method 4 a significant drawdown of the phreatic surface compared to the homogeneous seepage line can be observed even if all drainage elements have a hydraulic performance reduced by $50 \%$ (case b). Compared to the resulting seepage line of drainage elements with full hydraulic performance (case d) the differences in slope stability of the downstream slope should be insignificant.

But with a hydraulic performance of $Q_{B} / Q_{A}=0.1$ as measured in Installation-Test-B Method 3 the drawdown of the phreatic surface in case b) (reduced hydraulic performance of all drainage elements) compared to the phreatic surface of a homogeneous dyke structure is only marginal. Additional stabilizing effects on the slope stability of the downstream slope due to the subsequently installed drainage elements would be insignificant. The results concerning InstallationTest-B Method 3 support the results of the previous installation test (cf. Fig. 8) with equal hydraulic performance of the subsequently installed drainage element. Both installation methods are therefore not suitable for the proposed stabilisation technique.

However with Method 4 at least one suitable installation method was established. The impact of Method 4 on the hydraulic performance of the installed drainage element is acceptable. With a hydraulic performance of $50 \%$ the drawdown of the phreatic surface and therefore the stabilizing effects on the downstream slope are only lightly affected.

\section{Conclusions}

The feasibility of the proposed stabilisation technique was verified. With a numerical parameter study significant stabilizing effects induced by the drawdown of the phreatic surface were investigated. For a drainage length of $6.75 \mathrm{~m}$ it is demonstrated in an exemplary manner, that dependent on the distance between the drainage elements even under steady state seepage conditions and a water table at crest level at the upstream slope stability requirements of up-to-date technical standards can be fulfilled.

By means of tests on a natural scale a suitable installation method (Installation-Test-B Method 4) was established and a final verification of the hydraulic numerical model was 
accomplished. Furthermore, these tests showed that the installation method has a significant impact on the resulting hydraulic performance of the installed drainage element. Physical contact between the drainage element and the surrounding soil during the installation process should be avoided, in order to assure minimum impact on the hydraulic performance of the drainage element. Installation methods, which imply substantial contact of the drainage element with the surrounding soil during the installation process, can be the cause of insufficient hydraulic performance of the installed drainage element concerning the drawdown of the phreatic surface and can therefore not be recommended for industrial application.

Since all of the presented tests in natural scale were executed with one type of soil, the impact of the installation method on the hydraulic performance of the installed drainage element needs to be further verified for other soil types.

Acknowledgements. These investigations were carried out within the framework of the BMBF-projects 02WH0585, 02WH0586 and 02WH0587 (BMBF: German Federal Ministry of Education and Research). They were supported financially by the BMBF within the RIMAX-programme. The authors would like to offer their thanks for the financial support and the valuable cooperation of all partners involved.

Edited by: B. Merz

Reviewed by: H. Sellmeijer and another anonymous referee

\section{References}

Brauns, J. and Gottheil, K. M.: Wirkung von Streifendräns bei Dämmen und Deichen (Effectivity of Drain Strips in Dams and Dikes), Wasserwirtschaft, 79, 398-401, 1989.

Cedergren, H. R.: Seepage, drainage and flow nets, 3rd edn., WileyInterscience, 1988.
Dierickx, W.: Research and developments in selecting subsurface drainage materials. Irrigation and Drainage Systems, 6, 291-310, 1993.

Hungr, O.: An Extension of Bishop's simplified Method of slope stability analysis to three dimensions, Geotechnique, 37, 113117, 1987.

Kenney, C. T., Pazin, M., and Choi, W. S.: Design of Horizontal Drains for Soil Slopes, J. Geotech. Eng.-ASCE, GTll, 13111323, 1977.

Münchner Rück: Wetterrisiken in Mitteleuropa, Münchner Rückversicherungsgesellschaft, 2008.

Resnick, G. and Znidarcic, D.: Centrifugal Modeling of Drains for Slope Stabilization, J. Geotech. Eng.-ASCE, 116(11), 16071624, November 1990.

Scheuermann, A., Schlaeger, S., Huebner, C., Brandelik, A., and Brauns, J.: Monitoring of the spatial soil water distribution on a full-scale dike model, in: Fourth International Conference on Electromagnetic Wave Interaction with Water and Moist Substances, edited by: Kupfer, K. and Huebner, C., Weimar, Germany, 343-350, 13-16 May 2001.

Scheuermann, A., Huebner, Ch., Schlaeger, S., Wagner, N., Becker, R., and Bieberstein, A.: Spatial-TDR - Measurement of water content distributions in a full scale levee model using flat ribbon cables as elongated transmission lines, Water Resour. Res., Special Issue on Hydrologic Field Methods, 45, W00D24, doi:10.1029/2008WR007073, 2008.

Smith, T. W. and Stafford, G. V.: Horizontal drains on California highways, Journal of the Soil Mechanics and Foundations Division, ASCE, 83(3), 1-26, 1957.

TUD: Analyse der Deichbrüche an Elbe und Mulde während des Hochwassers 2002 im Bereich Sachsen, Forschungsbericht 2005/09 des Instituts für Wasserbau und Technische Hydromechanik der Technischen Universität Dresden, 2005.

Woersching, H., Becker, R., Schlaeger, S., Bieberstein, A., and Kudella, P.: Spatial-TDR moisture measurement in a large scale levee model made of loamy soil material, in: Proceedings: TDR 2006, 3rd International Symposium and Workshop on TDR for Innovative Soils Applications, Purdue University, USA, 17-20 September 2006, https://engineering.purdue.edu/ TDR/Papers/33_Paper.pdf, last access: November 2009. 